\title{
REMOÇÃO DE COR UTILIZANDO ENZIMA HORSERADISH PEROXIDASE E PERÓXIDO DE HIDROGÊNIO
}

\author{
A. R. PEREIRA ${ }^{1}$, L. YOKOYAMA ${ }^{2}$, E. M. ALHADEFF ${ }^{3}$ \\ ${ }^{1}$ Universidade Federal do Rio de Janeiro, Tecnologia de Processos Químicos e Bioquímicos, \\ doutorando. \\ ${ }^{2}$ Universidade Federal do Rio de Janeiro, EQ/Departamento de Processos Inorgânicos \\ ${ }^{3}$ Universidade Federal do Rio de Janeiro, EQ/Departamento de Engenharia Bioquímica \\ E-mail para contato: andrerpereir@yahoo.com.br
}

\begin{abstract}
RESUMO - Este trabalho consiste em avaliar as melhores condições do processo enzimático de descoloração do azul de metileno, utilizando a ferramenta estatística, no estudo da reação entre a enzima Horseradish peroxidase (HRP) e o peróxido de hidrogênio. Foram realizados três delineamentos de dois níveis para a obtenção das condições ótimas da reação. A análise dos resultados possibilitou observar uma correlação inversa entre o percentual de remoção de cor e a concentração de peróxido de hidrogênio utilizada, isto é, um melhor desempenho na descoloração do azul de metileno ao se reduzir a concentração de peróxido até $5,0 \mathrm{mg} / \mathrm{L}$. Foi verificado um percentual de descoloração de $23 \%$ com uma concentração de peróxido de hidrogênio igual a $5 \mathrm{mg} / \mathrm{L}$, atividade inicial da enzima igual a $20 \mathrm{U} / \mathrm{mL}$ no tratamento de $15 \mathrm{mg}$ de corante/L em meio aquoso. O modelo matemático prevê, nestas condições, uma remoção máxima de 21,3\%. Para nível de significância de $95 \%$ todos os efeitos e o modelo foram relevantes estatisticamente.
\end{abstract}

\section{INTRODUÇÃO}

Os processos industriais têxteis possuem uma necessidade ímpar de tratamento de seus efluentes, pois cerca de $20 \%$ da matéria-prima processada no tingimento de tecidos é perdida na forma de efluente (Barreto et al. 2011). Diversos processos oxidativos surgem para solucionar esta característica da indústria têxtil, dentre os processos estão os processos oxidativos utilizando enzimas.

A enzima Horseradish Peroxidase (HRP) é capaz de reagir com o peróxido de hidrogênio formando um composto intermediário (HRP-I) que ataca compostos aromáticos produzindo radicais e outro composto intermediário (HRP-II), também capaz de gerar radical, conforme modelo citado por Wu et al. (1997) e apresentado pelas três reações abaixo:

$$
\begin{aligned}
& \mathrm{HRP}+\mathrm{H}_{2} \mathrm{O}_{2} \rightarrow \mathrm{HRP}-\mathrm{I}+\mathrm{H}_{2} \mathrm{O} \\
& \mathrm{HRP}-\mathrm{I}+\mathrm{AH}_{2} \rightarrow \mathrm{HRP}-\mathrm{II}+\bullet \mathrm{AH}+\mathrm{H}_{2} \mathrm{O} \\
& \mathrm{HRP}-\mathrm{II}+\mathrm{AH}_{2} \rightarrow \mathrm{HRP}+\bullet \mathrm{AH}+\mathrm{H}_{2} \mathrm{O}
\end{aligned}
$$




\section{9 a 22 de outubro de 2014 \\ Florianópolis/SC}

As principais variáveis que influenciam nas reações com a enzima HRP em qualquer processo enzimático são o $\mathrm{pH}$ do meio e a temperatura. $\mathrm{O} \mathrm{pH}$ apresenta maior influência no grau de ionização dos grupamentos existentes na enzima ou até mesmo no seu centro catalítico; esta influência não se dá somente na enzima, mas o próprio substrato pode ser afetado pela concentração de íons $\mathrm{H}^{+}$. Elliott (2005) afirma que em uma reação bioquímica, a temperatura pode atuar de duas formas distintas: favorecendo a cinética da reação (comprovado pela equação de Arrhenius) e, no caso particular de reações enzimáticas, existe um limite no qual a temperatura começa a ser prejudicial à reação, levando a desnaturação da enzima e, portanto, acarretando perda no poder catalítico da enzima Conn (1976).

O objetivo deste trabalho é avaliar as melhores condições do processo enzimático de descoloração do azul de metileno (AM), utilizando ferramenta estatística, no estudo da reação entre a enzima horseradish peroxidase (HRP) e o peróxido de hidrogênio.

\section{MATERIAIS E MÉTODOS}

\subsection{A ENZIMA}

A Horseradish peroxidase (HRP) utilizada neste trabalho foi cedida pela Toyobo do Brasil. A HRP é classificada como uma enzima oxirredutase, que na presença de peróxido de hidrogênio é capaz de gerar compostos reativos de oxigênio, classificados como oxidantes fortes apresentando potencial de oxidação de até $2,42 \mathrm{~V}$, são capazes de oxidar várias substâncias orgânicas recalcitrantes (Gardingo, 2010).

\subsection{PLANEJAMENTO EXPERIMENTAL}

A partir dos melhores resultados de $\mathrm{pH}$ e temperatura na descoloração do corante azul de metileno (VETEC), obtidos pelos autores em trabalhos anteriores, foram realizados experimentos utilizando metodologia estatística aplicando planejamento experimental de dois níveis. A sequência de experimentos realizados visa identificar os efeitos da concentração do corante azul de metileno (AM), da concentração de peróxido de hidrogênio $\left(\left[\mathrm{H}_{2} \mathrm{O}_{2}\right]\right)$ e da atividade inicial da enzima (HRP) na remoção de cor do azul de metileno.

Foi realizado um total de três delineamentos de dois níveis para a obtenção das condições ótimas da reação. No primeiro e no segundo delineamento do planejamento experimental foram investigados somente os efeitos das variáveis independentes e suas respectivas importâncias estatísticas na faixa de estudo. No segundo e terceiro delineamentos, o planejamento foi realizado com apenas duas variáveis independentes, já que no primeiro delineamento a variável concentração de azul de metileno não foi significativa na faixa em estudo. No terceiro delineamento foi possível chegar à otimização do processo obtendo assim, superfície de resposta e respectivos efeitos utilizando o programa Statística ${ }^{\circledR}$. 


\subsection{REAÇÕES ENZIMÁTICAS}

As reações foram feitas em tubos de polipropileno com volume reacional de $20,0 \mathrm{~mL}$ em tampão de fosfato $\mathrm{pH} 5,0$ e na temperatura de $30,0^{\circ} \mathrm{C}$. O sistema reacional foi agitado a uma velocidade de 200 rpm em shaker "Nova Ética" modelo 430/RDBP e a reação tinha duração de 60 minutos. A remoção de cor foi determinada pela diminuição do pico da absorvância no comprimento de onda de 660nm, onde ocorre a maior absorção do azul de metileno. A leitura de absorvância foi realizada antes e após o término da reação, e a resposta da descoloração determinada em porcentagem de cor removida, calculada pela equação 1:

$\operatorname{Remoção~de~} \operatorname{cor}(\%)=\frac{A b s_{i}-A b s_{f}}{A b s_{i}} * 100$

(Equação 1)

Onde:

$\mathrm{Abs}_{\mathrm{i}}=$ Absorvância a $660 \mathrm{~nm}$ medida no tempo $\mathrm{t}=0$ minutos.

$\mathrm{Abs}_{\mathrm{f}}=$ Absorvância a $660 \mathrm{~nm}$ medida no tempo $\mathrm{t}=60$ minutos.

Ensaios preliminares realizados pelos autores mostraram que: a partir de $40 \mathrm{mg} / \mathrm{L}$ de peróxido de hidrogênio, a enzima HRP é inibida conforme previsto pela literatura (Wu et al., 1997; Bhunia et al., 2000; Liu et al., 2006); a partir de $20 \mathrm{mg} / \mathrm{L}$ de corante o pico de 660nm não é mais proporcional a cor do corante azul de metileno. A Tabela 1 mostra as concentrações de cada delineamento

Tabela 1 - Níveis e concentrações dos delineamentos realizados na degradação do corante azul de metileno utilizando HRP e peróxido de hidrogênio

\begin{tabular}{|c|c|c|c|c|c|c|}
\hline \multirow{2}{*}{ Delineamentos } & \multirow{2}{*}{ Parâmetros } & \multicolumn{5}{|c|}{ Níveis } \\
\cline { 2 - 7 } & & $-1,44$ & -1 & 0 & +1 & $+1,44$ \\
\hline \multirow{2}{*}{$\begin{array}{c}\text { Primeiro } \\
\text { delineamento }\end{array}$} & $\mathrm{H}_{2} \mathrm{O}_{2}(\mathrm{mg} / \mathrm{L})$ & - & 10,0 & 25,0 & 40,0 & - \\
\cline { 2 - 7 } & $\mathrm{HRP}(\mathrm{U} / \mathrm{mL})$ & - & 5,0 & 12,5 & 20,0 & - \\
\cline { 2 - 7 } & $\mathrm{AM}(\mathrm{mg} / \mathrm{L})$ & - & 5,0 & 10,0 & 15,0 & - \\
\hline \multirow{3}{*}{$\begin{array}{c}\text { Segundo } \\
\text { delineamento }\end{array}$} & $\mathrm{H}_{2} \mathrm{O}_{2}(\mathrm{mg} / \mathrm{L})$ & - & 5,0 & 15,0 & 25,0 & - \\
\cline { 2 - 7 } & $\mathrm{HRP}(\mathrm{U} / \mathrm{mL})$ & - & 20,0 & 35,0 & 50,0 & - \\
\cline { 2 - 7 } & $\mathrm{AM}(\mathrm{mg} / \mathrm{L})$ & - & 15,0 & 15,0 & 15,0 & - \\
\hline \multirow{2}{*}{$\begin{array}{c}\text { Terceiro } \\
\text { delineamento }\end{array}$} & $\mathrm{H}_{2} \mathrm{O}_{2}(\mathrm{mg} / \mathrm{L})$ & 0,9 & 5,0 & 15,0 & 25,0 & 29,1 \\
\cline { 2 - 7 } & $\mathrm{HRP}(\mathrm{U} / \mathrm{mL})$ & 1,9 & 5,0 & 12,5 & 20,0 & 23,1 \\
\cline { 2 - 7 } & $\mathrm{AM}(\mathrm{mg} / \mathrm{L})$ & - & 15,0 & 15,0 & 15,0 & - \\
\hline
\end{tabular}

Os cálculos das faixas de concentração foram realizados de forma que os pontos axiais do planejamento não fossem impossíveis, ou seja, que as concentrações e/ou atividade enzimática não fossem valores negativos. Para o primeiro delineamento, a concentração de corante igual a $20,0 \mathrm{mg} / \mathrm{L}$ foi escolhida como ponto axial do nível superior $(+1,68)$ e para os demais 
delineamentos, as faixas de estudo foram escolhidas a partir dos resultados gerados no primeiro delineamento.

\section{RESULTADOS}

\subsection{PRIMEIRO DELINEAMENTO}

A Figura 1 mostra a superfície gerada no primeiro delineamento para concentração de azul de metileno fixa em $15,0 \mathrm{mg} / \mathrm{L}$. É possível observar que o peróxido de hidrogênio não tem influência na remoção de cor do azul de metileno na faixa estudada, já à atividade inicial da enzima fornece elevados valores de remoção de cor a partir de $17 \mathrm{U} / \mathrm{mL}$, evidenciando a necessidade do aumento da atividade inicial da enzima. Na Tabela 2 onde se encontra os valores dos efeitos de cada variável e sua significância estatística para o intervalo de confiança de $95 \%$, nota-se que o aumento da concentração de azul de metileno provoca uma queda de cerca de $1 \%$ na descoloração.

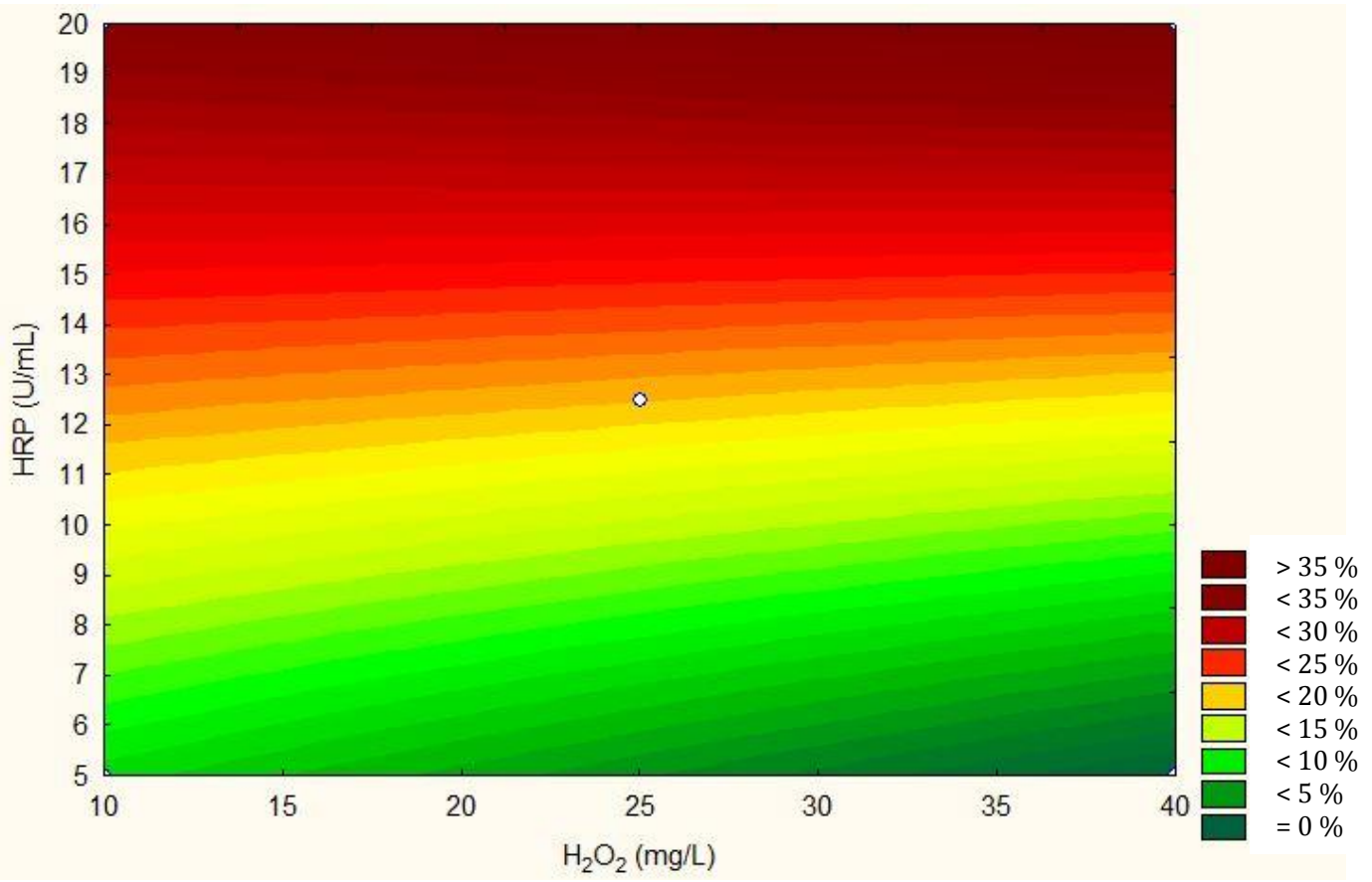

Figura 1 - Superfície gerada no primeiro delineamento com $\left[\mathrm{H}_{2} \mathrm{O}_{2}\right]=10,0 \mathrm{mg} / \mathrm{L}$ a $40,0 \mathrm{mg} / \mathrm{L}$; $\mathrm{HRP}=5,0 \mathrm{U} / \mathrm{mL}$ a $20,0 \mathrm{U} / \mathrm{mL} ;[\mathrm{AM}]=15,0 \mathrm{mg} / \mathrm{L}$ em $\mathrm{pH}=5,0$ e temperatura igual a $30,0^{\circ} \mathrm{C}$. 
Tabela 2 - Efeitos das variáveis e significâncias estatísticas observados para o intervalo de confiança de $95 \%$.

\begin{tabular}{|l|c|c|c|c|c|c|}
\hline \multirow{2}{*}{ Variável } & \multicolumn{2}{|c|}{ Primeiro Delineamento } & \multicolumn{2}{c|}{ Segundo Delineamento } & \multicolumn{2}{c|}{ Terceiro Delineamento } \\
\cline { 2 - 7 } & Efeito & $\begin{array}{c}\text { Significância } \\
\text { Estatística }\end{array}$ & Efeito & $\begin{array}{c}\text { Significância } \\
\text { Estatística }\end{array}$ & Efeito & $\begin{array}{c}\text { Significância } \\
\text { Estatística }\end{array}$ \\
\hline $\mathrm{AM}^{1}$ & $-0,87 \%$ & NSG & - & - & - & - \\
\hline $\mathrm{H}_{2} \mathrm{O}_{2}$ & $-4,2 \%$ & NSG & $4,7 \%$ & NSG & $-2,4 \%$ & SG \\
\hline $\mathrm{HRP}^{2}$ & $27,5 \%$ & SG & $-8,7 \%$ & SG & $8,0 \%$ & SG \\
\hline
\end{tabular}

1 - Azul de Metileno

2 - Atividade inicial da enzima HRP

SG - Significativo

NSG - Não significativo

$\mathrm{Na}$ faixa de concentração estudada no primeiro delineamento é possível observar que tanto a variável azul de metileno quanto a variável peróxido de hidrogênio não são significativas, porém foi decidido pelos autores que a concentração do corante azul de metileno não seria variada para o segundo delineamento, já o peróxido de hidrogênio seria necessário variar sua concentração, pois constitui um substrato essencial para o efeito oxidativo da HRP (Nicell et al. 1997). A concentração de azul de metileno foi fixada em $15,0 \mathrm{mg} / \mathrm{L}$ para o segundo delineamento e a faixa de concentração de peróxido de hidrogênio foi alterada para concentrações que fornece melhores remoções de cor, que segundo o resultado numérico do efeito está numa faixa abaixo da estudada.

\subsection{SEGUNDO DELINEAMENTO}

A Figura 2 gerada no segundo delineamento mostra que a região de maior remoção de cor é a região de menores concentrações tanto de peróxido de hidrogênio como de atividade inicial de enzima HRP. Pode-se afirmar que a descoloração do azul de metileno passa por um ótimo, pois ao aumentar a concentração de peróxido de hidrogênio há um aumento na descoloração de azul de metileno, e ao aumentar à atividade inicial da enzima, a descoloração do azul de metileno diminui. Resultados opostos ao encontrado no primeiro delineamento, reforçando a afirmativa da passagem pelo ótimo da reação. 


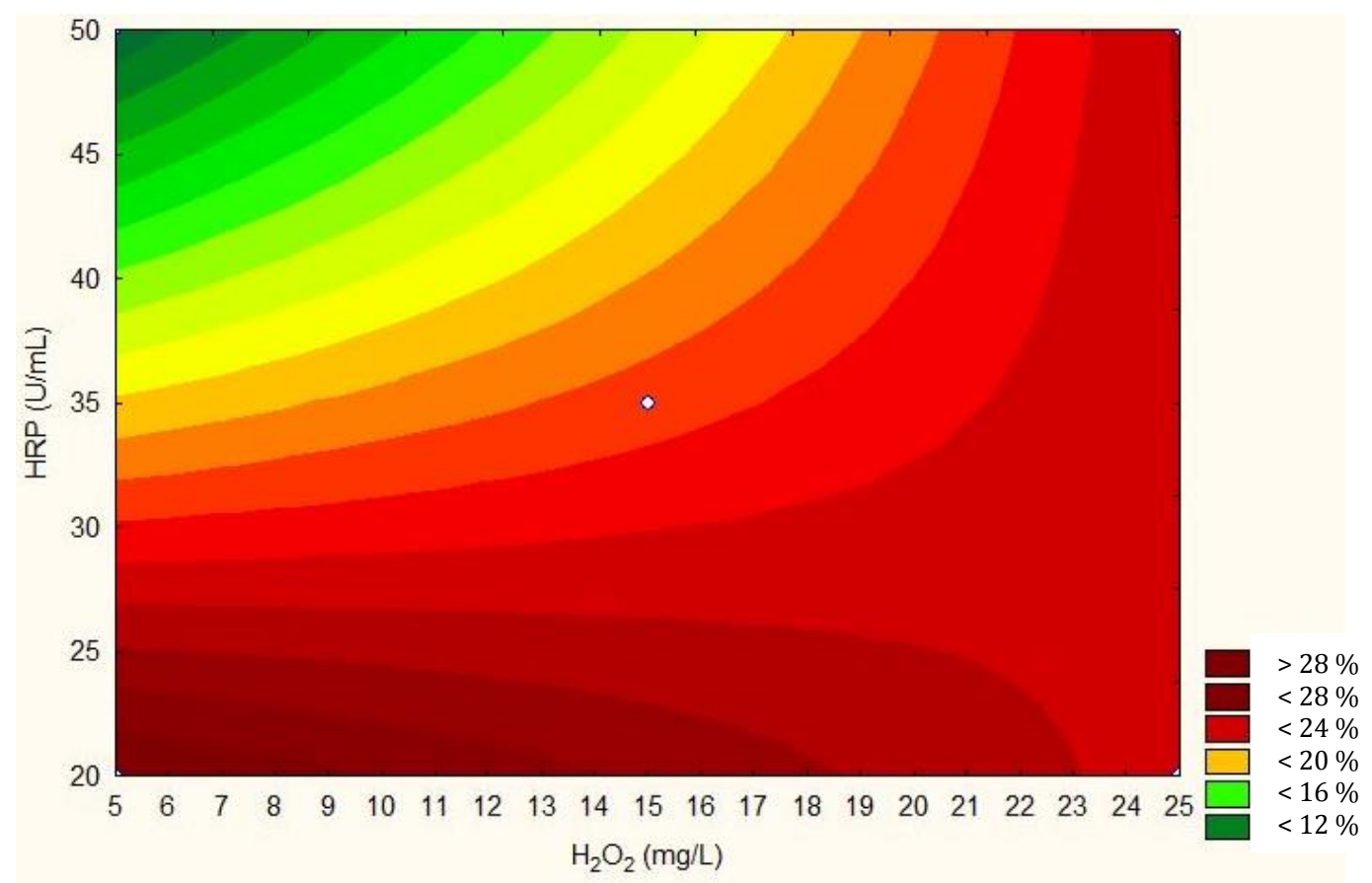

Figura 2 - Superfície gerada no segundo delineamento com $\left[\mathrm{H}_{2} \mathrm{O}_{2}\right]=5,0 \mathrm{mg} / \mathrm{L}$ a $25,0 \mathrm{mg} / \mathrm{L}$; $\mathrm{HRP}=20,0 \mathrm{U} / \mathrm{mL}$ a $50,0 \mathrm{U} / \mathrm{mL} ;[\mathrm{AM}]=15,0 \mathrm{mg} / \mathrm{L} \mathrm{em} \mathrm{pH}=5,0$ e temperatura igual a $30,0^{\circ} \mathrm{C}$.

O ponto ótimo da reação de descoloração do azul de metileno utilizando a enzima HRP e peróxido de hidrogênio está na faixa de concentração de peróxido de hidrogênio utilizada no segundo delineamento $(5,0$ a $25,0 \mathrm{mg} / \mathrm{L})$ e na faixa de atividade inicial de enzima utilizada no primeiro delineamento $(5,0$ a $20,0 \mathrm{U} / \mathrm{mL})$, formando assim a faixa a ser estudada no terceiro delineamento. Na Tabela 2 é possível observar que a concentração de peróxido de hidrogênio não é significativa para a faixa estudada neste segundo delineamento.

\subsection{TERCEIRO DELINEAMENTO}

O terceiro delineamento foi realizado com as faixas de concentração de peróxido de hidrogênio e atividade inicial de enzima definidas no primeiro e segundo delineamento. Os pontos axiais considerados neste terceiro delineamento possibilitaram avaliar os efeitos de interações entre as variáveis investigadas. A Figura 3 mostra a superfície gerada neste delineamento, com a curvatura sendo significativa para este intervalo. A Tabela 2 mostra que todas as interações são estatisticamente significativas, com isso é possível escrever a Equação 2, em termos codificados, gerada para a descoloração do azul de metileno. Para nível de significância de 95,0\% foram significativos os efeitos das concentrações de peróxido de hidrogênio (- 2,4\%), de enzima (8\%), e as interações entre peróxido de hidrogênio e enzima ($2,0 \%)$, e o efeito quadrático da enzima $(2,1 \%)$. O $\mathrm{R}^{2}$ do modelo foi de $95,92 \%$ que se ajusta ao modelo quadrático. 
(\%) Remoção de cor $=$

$\left(0,07-0,024\left[\mathrm{H}_{2} \mathrm{O}_{2}\right]+0,08[\mathrm{HRP}]+0,021[\mathrm{HRP}]^{2}-0,017\left[\mathrm{H}_{2} \mathrm{O}_{2}\right][\mathrm{HRP}]\right) * 100$

(Equação 2)
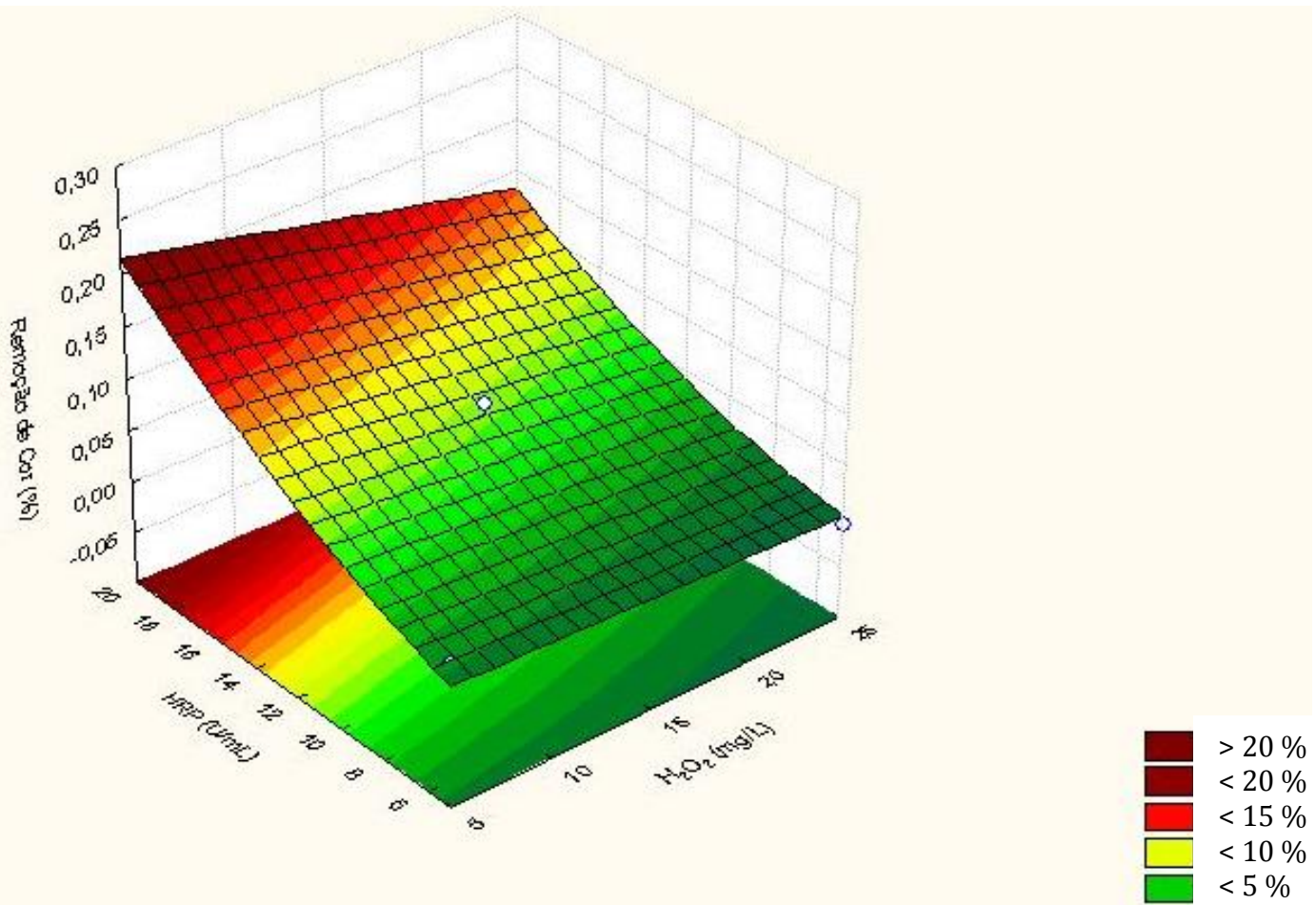

Figura 3 - Superfície gerada no terceiro delineamento com $\left[\mathrm{H}_{2} \mathrm{O}_{2}\right]=5,0 \mathrm{mg} / \mathrm{L}$ a 25,0 mg/L; HRP $=5,0 \mathrm{U} / \mathrm{mL}$ a $20,0 \mathrm{U} / \mathrm{mL} ;[\mathrm{AM}]=15,0 \mathrm{mg} / \mathrm{L} \mathrm{em} \mathrm{pH}=5,0$ e temperatura igual a $30,0^{\circ} \mathrm{C}$.

Kariminia e Yousefi (2010), utilizando planejamento fatorial associado à metodologia de superfície de resposta, estudaram a descoloração do corante "Orange 7" com peroxidase proveniente de fungo e encontraram um $\mathrm{R}^{2}$ de $97,18 \%$, conseguindo remover até $100 \%$ de cor do corante. Já Palvannan e Kalaiarasan (2014) utilizaram o planejamento completo fatorial compósito central e as superfícies de resposta geradas para otimizar a adição de estabilizadores à HRP na reação de degradação de fenol, obtendo $60 \%$ de remoção.

\section{CONCLUSÃO}

A remoção de cor do azul de metileno utilizando a enzima HRP e peróxido de hidrogênio foi de até 23,0 \% com uma concentração de peróxido de hidrogênio igual a 5,0 mg/L e atividade inicial da enzima igual a 20,0 U/mL com a concentração de corante igual a 15,0 mg/L. O modelo matemático prevê uma remoção de $21,3 \%$ de cor com as mesmas proporções. Esta remoção de cor é a máxima prevista pelo modelo na faixa estudada. 


\section{REFERÊNCIAS}

BARRETO, W. J.; BERNARDINO, N. D.; AFONSO, R.; Biodegradação de uma mistura de corantes têxteis usando o fungo ganoderma sp: um estudo cinético - Quimica Nova, Vol. 34, No. 4, 568-572, 2011.

BHUNIA A.; DURANI S.; WANGIKAR P.P.; Horseradish peroxidase catalyzed degradation of industrially important dyes. Biotechnology Bioengineer 72 pag. 562 - 567, 2000.

CONN, E. E.; STUMPF, P. K.; Introdução à Bioquímica. Editora Edgard Blücher LTDA, 1976

ELliOTT W. H.; ELLIOTT D. C.; Biochemisty and Molecular Biology. $3^{\mathrm{a}}$ ed. OXFORD University Press, 2005.

GARDINGO, M. F.; Tratamento de águas e efluentes contendo surfactantes através do sistema peróxido de hidrogênio. Dissertação de Mestrado, PUC-RJ 2010.

KARIMINIA H.; YOUSEFI V.; Statistical analysis for enzymatic decolorization of acid orange 7 by Coprinus cinereus peroxidase. International Biodeterioration \& Biodegradation 64, pag. 245-252, 2010

LIU J.; WANG T.; JI L.; Enhanced dye decolorization efficiency by citraconic anhydridemodified horseradish peroxidase. Journal of Molecular Catalysis B: Enzymatic 41 pag. 81-86, 2006

NICELL J.A.; WRIGHT H.; A model of peroxidases activity with inhibition by hydrogen peroxide. Enzyme and Microbial Technology 21 pag. 302-310, 1997.

PALVANNAN T.; KALAIARASAN E.; Removal of phenols from acidic environment by horseradish peroxidase (HRP): Aqueous thermostabilization of HRP by polysaccharide additives. Journal of the Taiwan Institute of Chemical Engineers 45, pag. 625-634, 2014

WU, Y.; TAYLOR K. E.; BISWAS N.; BEWTRA J.K.; Comparison of additives in the removal of phenolic compounds by peroxidase-catalyzed polymerization.Water Research. Vol. 31 Issue 11, Pages 2699-2704, 1997. 